\title{
ESTRATÉGIAS DE RACIONALIZAÇÃO DA CORRUPÇÃO NAS ORGANIZAÇÕES: UMA ANÁLISE DAS DECLARAÇÕES DE ACUSADOS EM CASOS DE CORRUPÇÃO NO BRASIL
}

\section{Strategies for Rationalizing Corruption in Organizations: An Analysis of Declarations of Accused in Cases of Corruption in Brazil}

\author{
Luiz Romeu de Freitas Júnior \\ Mestrando em Administração. \\ Universidade Federal de Uberlândia - UFU. Uberlandia, GO. Brasil. \\ e-mail:luizromeu26@msn.com
}

\section{Cintia Rodrigues de Oliveira Medeiros}

Doutora em Administração. Professora do Curso de Pós-Graduação. Universidade Federal de Uberlândia - UFU. Uberlandia, GO. Brasil. e-mail:cintia@ufu.br

\section{RESUMO}

Escândalos de corrupção envolvendo as diferentes esferas do poder público, assim como o poder privado, têm se tornado comum nos meios de comunicação. Além dos impactos políticos e socioeconômicos da corrupção, uma questão relevante para os estudos sobre o tema se refere a sua racionalização. Nesta pesquisa, nosso objetivo é explorar as justificativas para participação em esquemas de corrupção apresentadas por denunciados como forma de racionalização de seu envolvimento. Para isso, conduzimos uma pesquisa qualitativa com base intrepretativista, analisando o conteúdo de dez entrevistas concedidas por envolvidos em escândalos de corrupção no Brasil, nos anos de 2013 a 2016. A análise apontou certa similaridade no discurso utilizado pelos envolvidos, permitindo a constatação de categorias nas quais estes se enquadram (negação de responsabilidade, a negação de dano, as ponderações sociais, a negação do ato, a metáfora do equilíbrio e a postura cínica). Os resultados apontam que a partir de um questionamento, cada um dos envolvidos expõe sua versão do fato criando pontos em comum em seus discursos, que parecem surgir como resultado das interações e articulações sociais que os envolvem, contribuindo para um cenário favorável à perpetuação de corrupção nas organizações. A contribuição teórica desta pesquisa para os estudos organizacionais está em compreender a racionalização dos indivíduos para a perpetuação de um fenômeno não raro nas organizações, porém, ainda pouco explorado.

\section{ABSTRACT}

Corruption scandals involving the different spheres of public power, as well as private power, have become commonplace in the media. In addition to the political and socioeconomic impacts of corruption, a relevant issue for studies on the subject concerns its rationalization. In this research, our objective is to explore the justifications for participation in corruption schemes presented by denounced individuals as a way of rationalizing their involvement. To do this, we conducted a qualitative research based on intrepretativism, analyzing the content of ten interviews granted by those involved in corruption scandals in Brazil, from 2013 to 2016. The analysis pointed out a certain similarity in the discourse used by the participants, allowing the verification of categories (negation of responsibility, denial of harm, social considerations, denial of act, metaphor of balance and cynical stance). The results point out that from a questioning, each one of the involved exposes their version of the fact creating common points in their speeches, that seem to arise as a result of the interactions and social articulations that involve them, contributing to a scenario favorable to the perpetuation of corruption organizations. The theoretical contribution of this research to organizational studies is to understand the rationalization of individuals for the perpetuation of a phenomenon not uncommon in organizations, but still little explored.

Keywords: Corruption, Rationalization, Organizations.

Palavras-chave: Corrupção, Racionalização, Organizações. 


\section{INTRODUÇÃO}

As práticas de atos de corrupção podem institucionalizar-se nas mais variadas organizações, uma vez que independem de modelo de Estado, regime político ou contexto ideológico, sendo fruto de ações individuais ou coletivas e presentes tanto nas organizações públicas, bem como nas privadas. (SILVA et. al, 2005). O conceito de corrupção corporativa, como abordado por Tillman (2008), demonstra que a prática desses atos nas organizações, mesmo não estando expressamente proibidos através de leis ou registros legais, não os tornam menos prejudiciais a elas.

No Brasil, a partir da promulgação da Constituição de 1988 até os dias atuais, uma sucessão de escândalos de corrupção tem feito parte das manchetes dos noticiários, nas mais diferentes esferas da administração pública, assim como na iniciativa privada, evidenciando, dessa forma, os problemas relacionados ao fenômeno. Para além das consequências e de todos os desdobramentos, tanto políticos quanto socioeconômicos, uma questão que ainda carece de explicação é como as justificativas das pessoas envolvidas nesses escândalos racionalizam e fortalecem a prática do ato.

Um dos conceitos utilizados para o termo corrupção, mesmo no meio acadêmico, é proveniente da ONG Transparency International (2016) e que está disponível no site da organização, para a qual corrupção é "o abuso de poder confiado a alguém visando benefício pessoal, e pode ocorrer tanto em altos níveis de políticas governamentais bem como nas relações do dia a dia entre servidores públicos e cidadãos comuns". Esse conceito é questionado por autores, como Chadda (2004) que alega que essa perspectiva não contempla as realidades de sociedades em desenvolvimento, mas, sim, de sociedades tradicionais, o que pode indicar alguns vieses culturais e, consequentemente, ideológicos, impostos na sua formulação.

A partir de todas as particularidades que a corrupção envolve, diversos pesquisadores buscaram elaborar um corpo teórico com explicações para ofenômeno, porém devido a sua conceituação complexa, há uma certa dificuldade para alcançar esse objetivo, principalmente quando são consideradas as formas e situações diversas que ela envolve.
Nessa direção, e orientando-nos pela pesquisa de Anand, Ashforth e Joshi (2004), estabelecemos como objetivo desta pesquisa, explorar as justificativas para participação em esquemas de corrupção apresentadas por denunciados como forma de racionalização de seu envolvimento. Esses autores abordaram os temas utilizados por envolvidos para justificar a manutenção e perpetuação da corrupção, sendo que a racionalização envolve a relação dos discursos de justificação com cinco diferentes pontos, que seriam responsáveis por contribuir ao comportamento de perpetuação da corrupção nas organizações: a negação de responsabilidade, negação do dano, negação da vítima, as ponderações sociais, apelo para lealdades elevadas e a metáfora de equilíbrio. Segundo os autores, as táticas de socialização seriam ainda, uma forma de "doutrinar" os recém-chegados a uma organização a aceitar e praticar atos de corrupção, cooptação e compromisso.

Nesta pesquisa, que é de natureza qualitativa e de abordagem interpretativista, dirigimos nosso foco para as táticas de racionalização, analisando os discursos de envolvidos em escândalos de corrupção no Brasil, documentados em vídeos nas páginas eletrônicas de jornais impressos, bem como também das emissoras de televisão nacionais. A replicação do estudo realizado por Anand, Ashfort e Joshi (2004) permite conhecer os discursos na realidade brasileira, e o fato da realização desta pesquisa ocorrer uma década após o estudo que a originou, potencializa a análise da ocorrência ou não de mudanças nas táticas de racionalização em contextos distintos. Admitimos que nossa análise se ampara ainda em uma perspectiva como a de Torsello e Vernard (2015), que afirmam que os problemas relacionados com a corrupção, independentemente se ocorridos em esfera pública ou privada, estão em grande parte conectados às ações humanas, permitindo uma análise sob diversas lentes.

Estruturamos o artigo em três seções, depois desta introdução. Em seguida, fazemos uma abordagem dos conceitos de corrupção e as perspectivas teóricas sobre o assunto, tratando em seguida da perpetuação da corrupção nas organizações. Posteriormente, descrevemos os procedimentos da pesquisa, os resultados e encerramos com nossas considerações finais. 


\section{CORRUPÇÃO: VISITANDO CONCEITOS E PERSPECTIVAS TEÓRICAS}

Em uma perspectiva paradigmática realista (JIANG; LO; LI, 2012), Huntington (1975, p.72) define a corrupção, como "o comportamento de autoridades públicas que se desviam de normas aceitas a fim de servir a interesses particulares", esta conceituação é semelhante à apresentada pela ONG Transparency International (2016) e pelo The World Bank Bank Independent Evaluation Group (2006). No Brasil, ampliando um pouco mais o conceito, Silva (1994, p.21) define a corrupção como um "desvio de um padrão de conduta institucionalizado que se caracteriza principalmente pela utilização do público pelo privado com um manifesto propósito de favorecimento pessoal ou grupal". É perceptível como as conceituações de corrupção destacam a relação dicotômica entre as esferas pública e privada (TORSELLO; VENARD, 2015).

Ainda que ocorra em diversas áreas do conhecimento, a definição da corrupção quando ocorre de forma universal é frágil, pois quando assumimos que as ações humanas têm diversos pontos de vista, e por isso criam-se múltiplas moralidades, há um certo grau de variedade na percepção dos níveis de aceitação da corrupção, conforme a gradação em que ocorrem em determinadas culturas (TORSELLO; VENARD, 2015). A busca para a definição do termo corrupção é compartilhada por diversos autores em diferentes áreas, desde a economia (ROSE-ACKERMAN, 2006), contabilidade (OLIVEIRA, 2006), sociologia (NUMERATO, 2016) e os estudos organizacionais (ASHFORT et. al, 2008).

Em um âmbito econômico e político, por exemplo, Schwartzman (2008) afirma que há uma acentuação na percepção da corrupção, quando observada nas elites dos países mais pobres em comparação com os países mais desenvolvidos, o que pode trazer como consequência alguns impactos diretos nos investimentos privados e em políticas de ajuda internacional dos países que estão nesta condição. Nas ciências contábeis, os estudos possuem um caráter instrumental (OLIVEIRA, 2006; SILVA; BRAGA; LAURENCEL, 2009), apontando soluções para o problema através do uso e da otimização dos mecanismos de controle. Já os estudos organizacionais analisam a ocorrência da corrupção em dois diferentes níveis, o macro e o micro, sendo o primeiro orientado para as causas e transformações da corrupção na organização, enquanto que o segundo foca em ações individuais que influenciam na prática da corrupção (ASHFORT et. al, 2008).

Desde a década de 1960, esforços são dirigidos para se atingir um consenso sobre o significado do termo corrupção, no entanto a dificuldade em conseguir uma definição única e que o contemple de forma ampla é notável (JIANG; LO; LI, 2012). Brei (1996) aponta que dificilmente, obter-se-á uma "super definição" da corrupção, uma vez que sua análise e avaliação está sujeita a um julgamento de natureza moral. Essa dificuldade pode advir das várias lentes de percepção de comportamento das diferentes sociedades, pois uma sociedade corrupta pode não ser considerada como tal por outra sociedade, ou, ainda, por ela própria em um momento diferente de sua história (JIANG; LO; LI, 2012).

Quando as concepções sobre a corrupção atingem um consenso, elas atuam como valor normativo que surgem a partir de uma natureza linguística, assim, a partir do que é entendido como bom governo, origina-se um significado para o termo corrupção. A partir da sociologia das relações de poder e de acordo com as significações derivadas de um processo de interpretação realizado na esfera pública, é que se considera a compreensão da corrupção de acordo com os consensos normativos estabelecidos de forma deliberada que devem ser assumidos pela sociedade. Esses consensos definem os conteúdos de valores frente à moralidade política e o que é a contraparte normativa da corrupção (FILGUEIRAS, 2009).

Em meio às diversas teorizações sobre corrupção, que discutem sua definição, causas, consequências, custos e outros aspectos (AMUNDSEN, 1999; LAMBSDORFF, 2006) O'CONNOR; FISCHER, 2012), é relevante dirigir esforços para compreender porque essa prática se perpetua ao longo dos tempos. Nesse sentido, as justificativas das pessoas envolvidas em esquemas de corrupção oferecem caminhos para a busca de novos referenciais sobre o tema. Na sessão seguinte, tratamos de estudos que se orientam por essa perspectiva. 


\section{PERPETUAÇÃO DA CORRUPÇÃO NAS ORGAŇIZAÇÕES}

A corrupção pode ser explicada a partir da percepção que um indivíduo ou um grupo tem sobre ela, assim cada observador enquadrará sua percepção baseada em variadas perspectivas e é através das diferentes abordagens do tema que se identificará a perspectiva a ser adotada. Brei (1996) diz que há uma abordagem acadêmica que destaca os efeitos negativos da corrupção e tem uma preocupação com a análise das causas e redução do problema. A autora explica duas correntes: uma situa as causas no nível individual e social e a outra no nível institucional. A primeira se baseia na ideia de que existem na sociedade, crenças que farão com que ocorra um julgamento da corrupção de atos políticos ou administrativos, sendo essa postura uma consequência da falta de confiança, lealdade e consideração entre cidadãos e um Estado. Já as causas do nível institucional envolvem a aceitação da corrupção para a transação de negócios oficiais, culminando no domínio da corrupção no modo de operação da organização. Há, nesse caso, uma inversão, em que a violação da lei torna-se a regra de conduta.

As atividades do Estado e especialmente com o poder monopolista e discricionário desse Estado são na perspectiva de Tanzi (1998) uma das causas da corrupção. $\mathrm{O}$ autor discorre sobre alguns aspectos das atividades governamentais que proporcionam um campo extensivo para a ação da corrupção, dentre eles, as regulações e autorizações, a cobrança de taxas, as decisões de gastos, previsão de bens e serviços abaixo dos preços de mercado e o financiamento de partidos. Tanzi (1998) expõe ainda algumas causas indiretas da corrupção, tais como a qualidade da burocracia desempenhada em alguns países, quando são aquém do que o modelo burocrático propõe para a excelência; o nível salarial no setor público, que é confirmado pela relação de que, quanto menor o nível maior é a corrupção; as penalidades aplicadas; o controle institucional de órgãos de auditoria e apuração de irregularidades; a transparência das regras, leis e processos; e os exemplos de liderança.

Algumas dimensões relacionadas à corrupção são socialmente aceitas pelos indivíduos, sendo elas, o grau do envolvimento, o status dos envolvidos, as recompensas oferecidas, a seletividade dos incentivos, o local ou área da atividade e o nível de condenação (BREI, 1996). Partindo deste princípio Brei (1996) identifica que a corrupção por um indivíduo pode partir de um senso comum e, em muitos casos, é influenciada diretamente por padrões de certo ou errado. Nesse sentido, um fator que se relaciona com esse senso comum que caracteriza a corrupção em uma sociedade, pode ser a identidade nacional, objeto de estudo da pesquisa de Fischer et al. (2014) que a avaliou em relação à corrupção. Os autores perceberam que o nível de identificação da corrupção por uma população influencia no comportamento em relação às instituições e nas suas próprias ações em relação à corrupção, pois os indivíduos influenciam-se tanto por medidas de combate à corrupção, como pela influência dessa corrupção no contexto em que estão inseridos.

Além da identidade de uma nação, a renda, que foi o objeto de estudo de Maeda e Zigfield (2015), ao analisarem por meio de um estudo quantitativo diferentes países e a sua relação com a corrupção, é um outro fator que impacta na percepção de atos corruptos em diferentes sociedades. Em seu estudo os autores concluíram que os mais prejudicados pela corrupção (os indivíduos com menor renda) possuem uma percepção maior dos prejuízos provocados por ela nos países mais ricos, o que não se repetiu com os países mais pobres, nos quais os autores relataram como obscuras a relação renda e percepção da corrupção.

A corrupção em uma organização, assim como na sociedade de um modo geral, também parte da ação individual ou sistêmica/institucional. Quando ela parte da instância individual, se fortalece com as interações entre os indivíduos e é caracterizada como uma organização de indivíduos corruptos, já quando está em uma instância institucional, a própria organização é considerada corrupta, isto ocorre quando seus membros executam ações corruptivas que a beneficiam por meio da associação de indivíduos em pequenos grupos (PINTO; LEANA; PIL, 2008).

A normalização e perpetuação da corrupção nas organizações pode ser fortalecida por três processos, sendo eles a sua institucionalização, racionalização e socialização, os quais atuam de forma conjunta. A institucionalização ocorre quando as práticas de 
corrupção são admitidas como parte da rotina, já a racionalização é o uso pelos indivíduos de influências socialmente construídas como forma de legitimar seus atos; e a socialização é o processo no qual indivíduos recém-chegados na organização são estimulados a realizar e aceitar práticas corruptas (ASHFORT; ANAND, 2003).

Anand, Ashforth e Joshi (2004), depois de concluírem uma pesquisa sobre práticas de corrupção, perceberam que os envolvidos em escândalos de corrupção, geralmente, utilizavam-se de táticas de racionalização como justificativa dos atos de corrupção praticados. É importante destacar que o sentido de racionalização utilizado aqui diz respeito à trans- formação do que é um crime em algo considerado aceitável e que justifica "a forma de funcionamento das coisas". Assim, os autores desenvolveram um estudo sobre as táticas utilizadas que explicam a perpetuação da corrupção.

As táticas de racionalização da corrupção comumente utilizadas, conforme discutidas por Anand, Asforth e Joshi (2004) e que serviram de embasamento para a análise das entrevistas neste artigo, se dividem em seis: (i) negação de responsabilidade; (ii) negação do dano; (iii) negação da vítima; (iv) ponderações sociais; (v) apelo para lealdades elevadas e (vi) metáfora de equilíbrio e estão apresentadas no Quadro 1:

Quadro 01 Estratégias de racionalização

\begin{tabular}{l|l|l}
\hline Estratégia & Descrição & Exemplos \\
\hline $\begin{array}{l}\text { Negação de } \\
\text { responsabilidade }\end{array}$ & $\begin{array}{l}\text { Os atores envolvidos em comportamentos corruptos } \\
\text { percebem que não têm outra escolha a não ser partici- } \\
\text { par de tais atividades. }\end{array}$ & $\begin{array}{l}\text { "O que eu posso fazer? My arm is being twisted"." "Não é } \\
\text { da minha conta se a empresa faz suborno no exterior". }\end{array}$ \\
\hline Negação de dano & $\begin{array}{l}\text { Os atores estão convencidos de que ninguém foi pre- } \\
\text { judicado por suas ações portanto, suas ações não são } \\
\text { realmente corruptas. }\end{array}$ & $\begin{array}{l}\text { "Ninguém foi realmente prejudicado" } \\
\text { "Poderia ter sido pior" }\end{array}$ \\
\hline Negação de vítima & $\begin{array}{l}\text { Os atores negam qualquer tipo de culpa no ato, alegan- } \\
\text { do que a parte violada mereceu o que tenha ocorrido. }\end{array}$ & "Eles mereceram isso." EEles escolheram participar." \\
\hline Ponderações sociais & $\begin{array}{l}\text { Justifica-se o ato, através da alegação de que há práticas } \\
\text { piores no mesmo âmbito em comparação com a } \\
\text { corrupção praticada. }\end{array}$ & $\begin{array}{l}\text { "Você não tem o direito de nos criticar." "Outros são } \\
\text { piores do que nós." }\end{array}$ \\
\hline $\begin{array}{l}\text { Apelo para lealdades } \\
\text { elevadas }\end{array}$ & $\begin{array}{l}\text { Os atores argumentam que a violação das normas ocor- } \\
\text { reu na tentativa de atender os valores de superiores. }\end{array}$ & $\begin{array}{l}\text { "Nós respondemos a uma causa mais importante."“Eu } \\
\text { não poderia denunciar isso pela minha lealdade ao } \\
\text { meu chefe." }\end{array}$ \\
\hline Metáfora do Equilíbrio & $\begin{array}{l}\text { Os atores racionalizam o direito a entrar em com- } \\
\text { portamentos desviantes devido ao tempo e esforço } \\
\text { acumulados em seus trabalhos. }\end{array}$ & $\begin{array}{l}\text { "Nós já ganhamos o direito [de fazer isso]" "Está tudo } \\
\text { bem para mim usar a Internet para fins pessoais no } \\
\text { trabalho. Depois de tudo que eu faço trabalho de horas } \\
\text { extras" }\end{array}$ \\
\hline
\end{tabular}

Fonte: Anand, Ashforth e Joshi (2004, p. 41)

Segundo Anand, Asforth e Joshi (2004), a negação da responsabilidade seria a situação na qual os atores envolvidos em situações de corrupção concluem que não teriam outra escolha a não ser a participação nos esquemas de corrupção. Já a negação do dano há um convencimento, pelos praticantes dos atos, de que ninguém seria prejudicado por suas ações, justificando assim que as ações não seriam de fato corruptas. Na tática chamada de negação da vítima, os praticantes não assumem que suas ações produziram vítimas, na verdade, nessa situação, os pesquisados argumentam que a parte violada mereceu o acontecido. As ponderações sociais também seriam uma tática detectada nos discursos e envolve duas práticas como forma de justificação do ato: a primeira delas seria a condenação de quem estaria condenando a prática, sob a justificativa da segunda prática, que seria a uma comparação social seletiva, utilizando no discurso a justificativa de que há práticas piores, no mesmo âmbito, em comparação com a

1 Expressão que significa que a pessoa está sendo forçada a fazer algo que não quer fazer. 
corrupção praticada. $\mathrm{O}$ discurso de apelo à lealdade elevada utiliza o argumento, por quem praticou, de que houve a tentativa de utilizar um valor de ordem superior, ou seja, o ato foi praticado sob a justificativa de atender uma causa maior ou uma determinação hierarquicamente superior, independentemente de ser ilegal ou não. A justificativa baseada em um histórico de equilíbrio encerra a apresentação das categorias de racionalização e refere-se ao discurso cuja alegação pelos atores concentra-se no fato de que esses teriam direito a entrar em comportamentos desviantes em função de créditos acumulados em trabalhos anteriores ao escândalo.

\section{PESQUISANDO AS JUSTIFICATIVAS DOS ENVOLVIDOS}

Para alcançar o objetivo proposto, conduzimos uma pesquisa qualitativa com base intrepretativista (VERGARA; CALDAS, 2007), visto que esse tipo de pesquisa é uma ferramenta para entender o mundo e produzir conhecimento sobre ele (FLICK, 2009). O material empírico é composto de dez entrevistas concedidas por envolvidos em escândalos de corrupção no Brasil, as quais estão disponibilizadas em vídeos postados em sítios eletrônicos de emissoras de televisão e de jornais de grande circulação no Brasil. Para a seleção do corpus, buscamos na versão eletrônica do site G1(portal de notícias da Globo) e do site Uol (portal de notícias da Folha de S. Paulo), a escolha desses sites ocorreu exclusivamente em função do acervo em vídeos disponibilizado por eles, aumentando a possibilidade de encontrarmos o material a ser analisado, conforme o filtro estabelecido, que foi de vídeos postados no período de 01 de janeiro de 2013 a 31 de maio de 2016, colocando a palavra-chave "esquema de corrupção". Do resultado da busca, analisamos os títulos dos vídeos para descartar aqueles que não atendiam o critério de conter entrevistas de envolvidos em esquemas de corrupção no Brasil.

A seleção dos vídeos analisados levou em consideração ainda a ocorrência de escândalos de corrupção que tiveram destaque em níveis regionais e nacionais entre os anos de 2013 a 2016 e que caracterizam situações de corrupção no Brasil conforme a realidade desta década, tanto na esfera pública como privada. Dentre os dez vídeos selecionados, oito deles tratam de ações advindas de agentes públicos, e dois vídeos analisados referem-se a agentes da iniciativa privada, e as ocorrências em si envolvem prejuízo público em detrimento de interesses pessoais. As situações dos vídeos representam o que pode acontecer relacionado à corrupção nas organizações, assim como a atitude dos agentes envolvidos. Os vídeos foram submetidos à análise de conteúdo conforme Bardin (1979). Para operacionalizar a análise, assistimos os vídeos em duas etapas. A primeira etapa teve como objetivo certificar se a entrevista continha material relevante para alcançar o objetivo, ou seja, se os envolvidos ofereciam respostas sobre os motivos que os levaram a participar do esquema de corrupção. A segunda etapa teve como objetivo realizar a transcrição das entrevistas, as quais resultaram em setenta e oito laudas digitadas.

No Quadro 02, a seguir, relacionamos os vídeos analisados, com o título do vídeo, o link para acesso, o esquema de corrupção ao qual se refere, a data e o tempo de duração do vídeo.

Quadro 02 Vídeos analisados

\begin{tabular}{|c|c|c|c|}
\hline Título/Link & Esquema de corrupção & Data & Tempo \\
\hline $\begin{array}{l}1 \text { Fiscal investigado diz que gastava dinheiro de corrupção com diversão } \\
\text { http://g1.globo.com/sao-paulo/noticia/2013/11/fiscal-investigado-diz-que- } \\
\text { gastava-dinheiro-de-corrupcao-com-diversao.html }\end{array}$ & $\begin{array}{l}\text { Corrupção dos auditores da Prefei- } \\
\text { tura de São Paulo. }\end{array}$ & $24 / 11 / 2013$ & $10^{\prime}: 27^{\prime \prime}$ \\
\hline $\begin{array}{l}2 \text { As acusações são todas absurdas, diz Gabriel Chalita } \\
\text { http://noticias.uol.com.br/politica/ultimas-noticias/2013/05/10/gabriel- } \\
\text { chalita-no-poder-e-politica.htm }\end{array}$ & $\begin{array}{l}\text { Empresas que fizeram negócios } \\
\text { com a Secretaria da Educação do } \\
\text { Estado de São Paulo de } 2003 \text { a } 2006 .\end{array}$ & $10 / 05 / 2013$ & $61^{\prime}: 00$ \\
\hline
\end{tabular}

Fonte: elaborado pelos autores com base em dados de pesquisa 


\begin{tabular}{|c|c|c|c|}
\hline Título/Link & Esquema de corrupção & Data & Tempo \\
\hline $\begin{array}{l}3 \text { Anthony Garotinho dá entrevista ao RJTV - 1a Edição } \\
\text { https://globoplay.globo.com/v/3637903/ }\end{array}$ & $\begin{array}{l}\text { Esquemas de corrupção no estado } \\
\text { do RJ de } 1999 \text { a } 2002 .\end{array}$ & $18 / 09 / 2014$ & $12^{\prime}: 35^{\prime \prime}$ \\
\hline $\begin{array}{l}4 \text { Poder e Política: José Dirceu } \\
\text { https://www.youtube.com/watch?v=Q4Sxckn5SeU\&noredirect=1 }\end{array}$ & Escândalo do Mensalão & $10 / 04 / 2013$ & $74^{\prime}: 51^{\prime \prime}$ \\
\hline $\begin{array}{l}5 \text { Eduardo Cunha afirma que o dinheiro em contas da Suíça não é dele } \\
\text { http://g1.globo.com/jornal-da-globo/noticia/2015/11/eduardo-cunha-fala- } \\
\text { sobre-acusacoes-de-corrupcao-e-lavagem-de-dinheiro.html }\end{array}$ & $\begin{array}{l}\text { Corrupção e lavagem de dinheiro } \\
\text { pelo presidente da Câmara dos } \\
\text { Deputados Federais }\end{array}$ & 06/01/2015 & $10^{\prime}: 37^{\prime \prime}$ \\
\hline $\begin{array}{l}6 \text { Ex-funcionária afirma que pagamento de propina era prática na Odebrecht } \\
\text { http://g1.globo.com/politica/operacao-lava-jato/noticia/2016/03/pagamento- } \\
\text { de-propina-e-pratica-antiga-na-odebrecht-diz-ex-funcionaria.html }\end{array}$ & $\begin{array}{l}\text { Operação Lava Jato - Empreteira } \\
\text { Odebrecht }\end{array}$ & $27 / 03 / 2016$ & $10^{\prime}: 06^{\prime \prime}$ \\
\hline $\begin{array}{l}7 \text { Grupo é suspeito de fraudar notas fiscais para obter verba pública no RS } \\
\text { http://g1.globo.com/rs/rio-grande-do-sul/noticia/2016/03/grupo-frauda- } \\
\text { notas-fiscais-para-conseguir-dinheiro-publico-no-rs.html }\end{array}$ & $\begin{array}{l}\text { Fraude no estado do Rio Grande } \\
\text { do Sul para desviar verbas públicas } \\
\text { provenientes da Lei de Incentivo à } \\
\text { Cultura }\end{array}$ & $07 / 03 / 2016$ & 04:47 \\
\hline $\begin{array}{l}8 \text { 'Mal dá para sobreviver', diz vereador de Parauapebas sobre seu salário } \\
\text { http://g1.globo.com/pa/para/noticia/2015/05/mal-da-para-sobreviver-diz- } \\
\text { vereador-de-parauapebas-sobre-seu-salario.html }\end{array}$ & $\begin{array}{l}\text { Declaração de vereador de Pa- } \\
\text { rauapebas-PA, que posteriormente } \\
\text { foi acusado de envolvimento em } \\
\text { esquema de corrupção na cidade. }\end{array}$ & $07 / 05 / 2015$ & 03:01 \\
\hline $\begin{array}{l}9 \text { Ex-contadora de Alberto Youssef se diz arrependida } \\
\text { http://mais.uol.com.br/view/jinmenm98vmk/excontadora-de-alberto-youssef- } \\
\text { se-diz-arrependida-0402CC9C3262DC995326?types=A\& }\end{array}$ & $\begin{array}{l}\text { A contadora de Alberto Youssef } \\
\text { (que teve seu nome ligado ao even- } \\
\text { tos investigados pela Operação Lava } \\
\text { Jato) informa sobre sua participação } \\
\text { no esquema de corrupção coman- } \\
\text { dado por ele. }\end{array}$ & $10 / 02 / 2015$ & 05:49 \\
\hline $\begin{array}{l}10 \text { Vereadores de Nova Prata, RS, são suspeitos de falsificarem recibos de } \\
\text { táxis em Brasília } \\
\text { http://g1.globo.com/rs/rio-grande-do-sul/rbs-noticias/videos/v/vereadores- } \\
\text { de-nova-prata-rs-sao-suspeitos-de-falsificarem-recibos-de-taxis-em- } \\
\text { brasilia/4356619/ }\end{array}$ & $\begin{array}{l}\text { Vereadores de Nova Prata-RS, envol- } \\
\text { vidos em esquema de falsificação } \\
\text { de recibos de táxi em viagens a } \\
\text { Brasília. }\end{array}$ & 29/07/2015 & 04:19 \\
\hline
\end{tabular}

Fonte: elaborado pelos autores com base em dados de pesquisa

As categorias foram estabelecidas previamente, visto que nos orientamos pela revisão da literatura buscando reconhecer as táticas de racionalização conforme Anand, Asforth e Joshi (2004) e outras que pudessem emergir na análise do material e que não foram identificadas pelos autores. Para a análise do material, percorremos os seguintes passos: (1) agrupamos as ideias identificadas no material empírico a partir das seis categorias analíticas; (2) identificamos os núcleos de sentido de cada categoria. Nessa etapa, identificamos um núcleo de sentido que não correspondia a nenhuma das estratégias de racionalização reconhecidas por Anand, Asforth e Joshi (2004), a qual nomeamos de Postura Cínica.aAinda, a "negação do ato" foi uma estratégia percebida nos vídeos e não abordada naquele estudo. A pesquisa para $o$ levantamento do material ocorreu entre os dias 21 a 24 de maio de 2016.

\section{TÁTICAS DE RACIONALIZAÇÃO DE ENVOLVIDOS EM ESQUÉMAS DE CORRUPÇÃO NO BRASIL.}

Conforme Anand, Ashforth e Joshi (2004), empregados que cometem atos de corrupção se engajam em táticas de racionalização, isto é, esses descrevem suas ações de forma que não pareçam ser não éticos, em uma tentativa de neutralizar sentimentos negativos ou arrependimentos sobre seu comportamento. Para os autores, as pessoas que utilizam essas táticas, muitas vezes, se convencem que sua conduta é justificada. A seguir, apresentamos as táticas de racionalização utilizadas pelos envolvidos em esquemas de corrupção no Brasil que protagonizaram os vídeos analisados. 


\subsection{Negação de responsabilidade}

Anand, Ashforth e Joshi (2004) explicam que a tática de negação de responsabilidade envolve a racionalização na qual as pessoas convencem-se de que estão participando de atos de corrupção devido às circunstancias, o que pode envolver um sistema coercitivo, em muitos casos, os indivíduos não se consideram como autores da corrupção, mas, sim, como moralmente responsáveis, sendo forçados a errar pela ocasião.

O vídeo 6, que expõe o esquema de corrupção na empreiteira Odebrecht, apurado a partir de Março/2016, em uma das fases da Operação da Polícia Federal, denominada Operação Lava-Jato, expõe um discurso nessa categoria da negação de responsabilidade. Essa tática é evidenciada quando em uma denúncia de uma ex-funcionária da empreiteira, que trabalhou na organização de 1979 a 1990, na qual afirma possuir provas de um esquema de corrupção na empresa que ela teria testemunhado e feito parte. A entrevistada, aos 04 ': 15 " do vídeo, é questionada por qual motivo ficou com todos os documentos que alega ser prova, ao que ela responde: "Quando eu fui demitida da empresa, vieram dentro dos meus pertences pessoais. Quando eu cheguei em casa, eu percebi que tinha esses papéis da empresa. Então, eu não vi mais como devolvê-los".

Aos $07^{\prime}: 10$ ”, a entrevistadora pergunta se a entrevistada acredita que podem haver pagamentos que não são ilegais na lista que ela apresentou, e ela responde: "Acredito que não. Naquela relação, todos eram caixa dois". A entrevistadora então pergunta: "Como a senhora se sentia movimentando todo aquele dinheiro sabendo que era propina?”. A resposta da entrevistada é lacônica: "Constrangida". Prosseguindo, aos 09':32” do vídeo, a entrevistadora questiona: "Alguém chamou a senhora e disse: olha, a senhora vai participar disso, disso e disso. É preciso ter cuidado?”. A entrevistada responde: "Não, não. A coisa era feita abertamente. Todo mundo sabia na empresa. As pessoas dentro do departamento financeiro sabiam e algumas pessoas também fora sabiam que a empresa sempre trabalhava com caixa dois".

Com as duas últimas declarações da entrevistada, conseguimos categorizar o seu discurso no que Anand, Ashforth e Joshi (2004) reconheceram como negação de responsabilidade, pois a envolvida no esquema dizia-se constrangida em fazer parte do esquema, no entanto, afirma que, no âmbito da organização em que estava, a prática de corrupção da qual ela fez parte era de conhecimento de várias pessoas e era tratada dentro da normalidade, ou seja, o sistema da organização seria coercitivo nesse sentido.

\subsection{Negação de dano}

Nesta tática de racionalização, conforme Anand, Ashforth e Joshi (2004), o ator convence-se de que ninguém estaria realmente prejudicado por sua ação e, sendo assim, sua ação não se configura como corrupta. Uma variante da tática de negação do dano pode ser exemplificada através da entrevista do vídeo 5 , quando o entrevistado, o então presidente da câmara dos deputados no Brasil, Eduardo Cunha, argumenta que as acusações de corrupção e lavagem de dinheiro não procedem, pois, apesar de haver dinheiro em uma conta sua no exterior e esse não ter sido declarado à Receita Federal e ao Banco Central do Brasil, não se configura um ato corrupto, visto que ele não seria proprietário do dinheiro, consequentemente, não obstruindo a informação da Receita, prevalecendo a lógica de que se o dinheiro não é dele, não houve dano ao não declará-lo.

Aos 03':52" do vídeo 5, o acusado, quando perguntado sobre a propriedade do dinheiro, responde "Não, eu sou o dono do dinheiro, não. Eu sou usufrutuário em vida, nas condições determinadas". Prosseguindo, o entrevistador, aos 06':50" de entrevista pondera:

Deixa eu contrapor duas posições diferentes em relação ao argumento do senhor, presidente. O Banco Central afirma que em todos os casos é preciso fazer uma declaração do beneficiário residente. $\mathrm{O}$ senhor é o beneficiário desses dois fundos. Agora apenas do Netherton, que é o que permanece. E também existe uma visão por parte do Ministério Público de que é preciso fazer a declaração do trust justamente para que esse trust não seja usado para esconder ativos no exterior.

\section{O Entrevistado responde que:}

Veja bem, eu discordo dessa interpretação, não sou só eu, os advogados também discordam disso. No caso, nós pegamos o advogado na própria Suíça, que fez o seu parecer com relação a situação contratual existente. Esse parecer está em inglês, com 
suas documentações todas, tem sua tradução em português, que está muito claro que eu não sou proprietário nominal dos ativos, que eu não detenho conta, obviamente eu não detenho conta e, não detendo ativo, eu não tenho que declarar. Então, essa é uma discussão, o trust é muito antigo no mundo.

\subsection{Ponderações sociais}

Conforme Anand, Ashforth e Joshi (2004), as táticas de racionalização denominadas ponderações sociais ocorrem de duas maneiras. A primeira delas ocorre quando há um questionamento pelos condenados quanto àqueles que os estão denunciando, lançando dúvidas sobre a legitimidade do autor da denúncia. Nesse sentido, se a legitimidade de quem denuncia é questionável, o argumento também o seria. Assim, os indivíduos podem caracterizar a lei vaga, complexa demais, inconsistente, raramente aplicada, punitiva, ou basear a denúncia em motivações políticas, sustentando, assim, a ideia de que a acusação ou condenação seria maldosa. Considerando a perspectiva de que a lei estaria errada, então o fato de contrariá-la não seria uma conduta antiética. A segunda forma de ponderação social é a comparação social seletiva, que ocorre quando há um confronto de impressões negativas de si mesmos com demais acusados que teriam provocado uma situação ainda pior, para demonstrar a máxima de "que não estamos tão ruim".

Nas entrevistas analisadas, observamos como ponto comum a todos os acusados a alegação de que seriam vítimas de adversários políticos, que estariam conspirando contra eles, o que se enquadra na primeira categoria das ponderações sociais. Mesmo diante de acusações e de provas legais, em algumas situações, envolvendo até mesmo a condenação dos acusados, esses continuam declarando-se inocentes, afirmando que se baseiam na tese de que há uma perseguição, deixando em segundo plano as acusações que são legalmente fundamentadas.

Por exemplo, no vídeo 02, a partir dos 02:10, o entrevistador faz algumas perguntas sobre as acusações de recebimento de propina do acusado Gabriel Chalita:

Entrevistador: Há no momento uma dezena de inquéritos no MP em SP apurando fatos que relacionam o Sr. Há por exemplo suspeitas ou acusação de enriquecimento ilícito, teria recebido dinheiro ou favores de editoras que forneciam para a Secretaria de Educação de São Paulo, quando o sr. Esteve a frente desta pasta de 2002 a 2006. Todas as explicações que o senhor deu até agora, de acordo com alguns analistas que acompanham o caso, não foram conclusivas. Porque que o sr não deu essas explicações completas até hoje?

GC: Vamos lá, acho até que é importante este espaço para dar estas explicações não é? Primeiro é assim, é importante que se coloque como é que começou a história dessas denúncias, eu fui candidato a prefeito de SP e durante a campanha eleitoral muitas pessoas me ligaram dizendo que o Ivo Patarra que trabalhava na campanha do candidato José Serra, ele estava entrevistando pessoas da Secretária de Educação que haviam trabalhado comigo pra saber coisas da minha gestão e sempre essas pessoas me diziam assim, olha, ele quer saber de gente que saiu da secretária brigado com você, eu na época até falei isso com a jornalista Vera da Folha, com o Fábio do painel: Será que estão montando um dossiê contra mim? E esse dossiê foi montado pelo Ivo Patarra que trabalhava com o Walter Feldman, que trabalhava com o Serra na campanha e é um dossiê de quase 500 páginas, absolutamente folclórico, para se ter uma ideia esse denunciante que apareceu na imprensa inclusive de óculos escuros, dizendo que estava sendo ameaçado de morte por mim, eu acho que quem me conhece não imagine que eu. Ele foi uma parte desse processo, ele foi tantas vezes no MP para corrigir as informações. ....Eu nunca tive dinheiro fora do Brasil, agora aí você fala assim, mas como é que você dá uma explicação sobre isso? O que é que eu tenho que fazer? Tenho que ir a China pegar uma relação do sistema bancário chinês para colocação disso não é? ... As acusações são todas absurdas e eu tenho absoluta convicção de que são, não é a primeira vez que eu tive denúncias no MP, eu já tive denúncias no passado e na verdade minha vida é toda tranquila, eu não tenho nenhuma ação. Eu tenho muita tranquilidade pois não há nenhuma ação e que os inquéritos serão arquivados (TRANSCRIÇÃO VIDEO 2).

Nesse trecho do vídeo, observa-se que o acusado apoia-se na explicação de que seu concorrente político teria montado um dossiê contra ele, de forma a alegar falsidade nas denúncias prestadas. Outro caso semelhante, porém que aprofunda a utilização do discurso de perseguição política, é aquele contido no do vídeo 04 , na qual observam-se, a partir do início da entrevista (aos 2:30), trechos nos quais o entrevistado alega sua inocência, mesmo estando condenado no caso, de corrupção. O entrevistador pergunta: "na fase atual do processo do mensalão, agora, são os recursos. A sua defesa vai apresentar recursos. O sr. está com alguma esperança de ter sucesso?” (TRANSCRIÇÃO VÍDEO 4). Ao que o entrevistado responde:

Vai apresentar os recursos, tantos os embargos declaratórios como, depois, os infringentes. Depois de transitado em julgado, nós vamos para a revisão criminal. E vou bater às portas 
também na Comissão Internacional de Direitos Humanos para ir ao Tribunal Penal Internacional de San José. A minha expectativa é que a justiça apareça, porque eu fui condenado... Não é que eu fui condenado sem provas, como disse o ministro do Supremo, que os réus queriam que as provas aparecessem, como se não fosse o óbvio, que cabe à acusação apresentar as provas e comprovar o crime. Não houve crime, eu sou inocente. Me considero um condenado político. Foi um julgamento de exceção, foi um julgamento político. A cada dia eu me convenço mais disso, porque os fatos comprovam isso (TRANSCRIÇÃO VÍDEO 4).

O acusado reforça sua tese de inocência quando questionado sobre a alegação de que as provas contra ele em seu processo estariam incorretas. Conforme a pergunta feita pelo entrevistador: "Mas, veja só, o Supremo não considerou provas materiais os pagamentos feitos pela Visanet? Não foi dinheiro que o Supremo considerou público e usado indevidamente?", o entrevistado argumenta: "Primeiro, não é dinheiro público. A Visanet é uma empresa privada". O entrevistador, mais uma vez, questiona: "Mas o Supremo não o considerou [o dinheiro] como público?", ao que o entrevistado responde:

Mas o Supremo cometeu um erro jurídico gravíssimo, que nós vamos levar isso à revisão criminal. Primeiro, o dinheiro não é público, é privado. Alguém que deve para a Visanet está inscrito na dívida ativa da União? Isso é ridículo. Segundo, há provas, e elas são apresentadas agora já nos recursos e na revisão criminal, que todos os serviços foram prestados. Há provas. A campanha do Ourocard. [...]

Nesse caso, apoiando-se na ideia de que a justiça cometeu um erro, o acusado fundamenta a sua inocência. Ainda nessa categoria, cabe também a análise de um trecho do vídeo 03, no qual a entrevistadora faz a seguinte pergunta ao ator envolvido no esquema:

A pergunta é: a sua mulher foi condenada no ano passado por improbidade administrativa, a denúncia era a seguinte: Um contrato sem licitação para a montagem de 254 salas de informática na fundação Euclides da Cunha. A Justiça diz que não identificou, não conseguiu comprovar que estas salas tivessem sido de fato montadas. A Rosinha foi então condenada a ressarcir os prejuízos aos cofres públicos e teve os direitos políticos suspensos por 05 anos, o ex-secretário de Educação Cláudio Mendonça, também foi condenado neste caso, candidato, denúncia na educação, denúncia na saúde, denúncia na segurança. Pergunto ao Sr. o senhor e a sua mulher fiscalizaram mal o trabalho das pessoas que escolheram para o primeiro escalão do governo ou escolheram mal essas pessoas?
Sendo a resposta do entrevistado:

Eu gostaria de saber onde é que foi parar esse dinheiro, porque olha, quem comprou fazenda foi o Pisciane, o milionário o "Rei do Gado", quem comprou casa em Mangaratiba foi o Sérgio Cabral, lanchas, iates, vive viajando para Paris, quem montou uma fazenda cinematográfica mostrada pela Veja, foi o Paulo Melo. Eu levo uma vida normal de classe média, eu devo ser incompetente para roubar, porque se você diz isso tudo e eu não tenho onde esse dinheiro está.

A entrevistadora, faz um novo questionamento: "Candidato sobre este caso, eu entendo que o Sr. queira se estender, o Sr. não acha importante esse momento para esclarecer para o telespectador?". Ao que o entrevistado reponde:

Estou esclarecendo, eu sou vítima de muitas perseguições, o sistema brasileiro é acusação que cabe ao promotor, você está falando de acusações, a defensoria pública ou o advogado defende e o juiz julga. Por exemplo, acusação todo mundo tem, agora mesmo acusaram a Globo de estar envolvida em um desvio milionário, laranjas e paraísos fiscais, eu não sei se a Globo é culpada eu até acho que é, mas é uma opinião minha, quem vai dizer isso é o juiz, não sou eu, né”.

Nesse ponto, mais uma vez, evidencia-se a utilização da justificativa de perseguições para as acusações que existem contra ele.

$\mathrm{O}$ vídeo 10 também apresenta uma declaração que utiliza o mesmo discurso. Aos 02':54" do vídeo, um acusado de participar de um esquema de vereadores que fraudavam recibos de táxi é questionado pelo entrevistador se há a sua assinatura nos recibos apresentados, ao que o acusado responde "Claro que não! Claro que não". O entrevistador, então, questiona porque a perícia está dizendo o contrário, e o acusado responde "Porque essa perícia não é aqui do estado, a perícia quem contratou foi um vereador aqui da casa”.

\subsection{Negação do ato}

Identificamos no material analisado, uma tática de racionalização da corrupção que consiste em uma modalidade praticada quase que de forma instantânea e destaca-se como uma reação imediata que precede o uso das demais práticas, conforme inicia-se o processo de investigação, com a reunião das provas e a acusação formal dos atores envolvidos. 
Essa tática pode ser reconhecida como a negação do ato e consiste em um discurso que nega, mesmo que diante de provas iniciais, a execução do ato.

No vídeo 10, que trata do esquema de falsificação de recibos de táxis por vereadores de Nova Prata - RS, há uma exemplificação dessa situação, quando, aos 01':09" do vídeo, o entrevistador questiona um dos acusados sobre o reconhecimento do recibo, e esse responde: “Conheço, R\$ 160,00”. Em seguida, o entrevistador questiona o motivo do mesmo recibo ter grafias diferentes, ao que o acusado responde: "Olha eu digo ao senhor que a grafia aqui foi do proprietário do táxi”. O entrevistador, mais uma vez, questiona, ressaltando o fato de a perícia ter reconhecido a assinatura como dele. $\mathrm{O}$ acusado responde: "Por mim, com certeza eu garanto que não foi". Aos 2':21" do vídeo, um outro acusado é questionado se reconhece sua letra no recibo, o que foi constatado pela perícia, e ele responde: "Não! Essa letra não é minha, esse recibo não fui eu quem fiz e essa letra não é minha!".

No vídeo 07 , que trata do esquema de corrupção do estado do Rio Grande do Sul, no qual empresários, produtores culturais e políticos forjariam notas fiscais para desviar verbas de eventos financiados com dinheiro público, pela Lei de Incentivo à Cultura (LIC), um professor que orquestrava o esquema e um vereador da cidade de Rodeio Bonito-RS são surpreendidos pelo repórter que gravou todo o esquema de forma anônima e que, após revelar-se, questiona, o professor e o vereador, aos 04':04" de vídeo, se eles fraudaram a Lei de Incentivo à Cultura. O professor entrevistado responde: "Não, eu não fraudo Lei de Incentivo à Cultura”, e o vereador também responde que: "Eu só estava acompanhando, eu não participo disso aí".

O que se observa nos dois vídeos (7 e 10), e é importante destacar, é que essa tática, aparentemente, é utilizada quando o acusado ainda não construiu um discurso sólido sobre o ato praticado. Assim, essa parece ser uma via mais rápida para tentar racionalizar o ato que pode ser questionado posteriormente e possuir um outro tipo de racionalização.

\subsection{Metáfora de Equilíbrio}

A tática de racionalização de metáfora de equilíbrio, conforme Anand, Ashforth e Joshi (2004) é caracterizada como a tentativa de justificar o ato corrupto, na crença que há, por parte do praticante, um amparo nas suas obras realizadas, bem como no desempenho de sua função e que essas, por sua vez, dariam o crédito para que houvesse uma compensação quando praticados os atos de corrupção. O vídeo 8 exemplifica essa tática, em uma declaração polêmica de um então vereador da cidade de Parauapebas-PA, que, aos 00:30" de vídeo afirma: "O valor que o vereador ganha aqui, se ele não for corrupto, ele mal se sustenta durante o mês". Aos 01':40" de vídeo, é exposta outra declaração do vereador que complementa "O vereador, para sobreviver com o salário de R 7.800 aqui dentro desta casa, com o padrão de vida que depois de eleito ele tem e não é só eu, a gente dá mal para sobreviver".

Finalizando, aos 02':20" do vídeo 8 , o vereador ainda explica à reportagem o seu raciocínio: "Se for para eu sobreviver apenas com esse salário, com certeza absoluta eu não passaria o padrão de vida que eu levo hoje". Esse mesmo vereador foi preso em 26/05/2015, acusado de estar envolvido em um esquema de corrupção na cidade de Parauapebas-PA, conforme a matéria $(G 1,2015)$. Nesse caso, nota-se a tentativa de valorizar o cargo para justificar que a remuneração, não sendo o suficiente, não resta outra alternativa a não ser a prática da corrupção.

Conforme Anand, Ashforth e Joshi (2004), uma variação dessa tática de racionalização se configura quando o praticante do ato se ampara na situação social da organização ou do indivíduo para o qual presta serviço, acreditando que o seu vínculo com ele poderá isentá-lo das sanções da legislação, pois esse estaria em uma situação acima da lei.

No vídeo 09, que é referente a uma entrevista com a ex-contadora do doleiro Alberto Youssef, um dos delatores da Operação Lava-Jato, a partir dos 03 ':43" do vídeo, a contadora afirma que sabia dos negócios ilegais do doleiro: “ Eu sabia qual era a atividade do Alberto, isso é fato. A partir de $2012 \mathrm{eu}$ sabia exatamente qual era a atividade do Alberto.". Aos $04 ': 18$ ", a ex-contadora é questionada pelo entrevis- 
tador sobre o arrependimento, pedindo que ele colocasse o grau de 0 a 10. A entrevistada responde que:

\begin{abstract}
Eu vou colocar assim, o meu arrependimento pelo meu lado profissional é 10, é 11, eu tinha uma carreira muito boa, eu tinha um nome muito bom na área de imposto de renda, especialmente imposto de renda voltado pra área do mercado de capitais, eu sempre tive um trabalho muito bom. E hoje a imprensa me puniu, a sociedade me puniu, os meus clientes me puniram, o banco me puniu, então o meu arrependimento nisso é 10 .Talvez 11 ou 12. Por outro lado, pelo lado de ter ido de ter contado a verdade, de estar contando a verdade aqui para você, isso me alivia um pouco mas não paga a conta.
\end{abstract}

O conteúdo do vídeo 9 ilustra o que seria a variação da tática de metáfora de equilíbrio, quando a entrevistada não afirma que praticou o ato de corrupção por se sentir resguardada pelo seu então cliente, o doleiro Alberto Youssef, no entanto, deixa claro que tinha um status profissional e, possivelmente, ao tomar conhecimento das atividades ilícitas de seu cliente, continuou sua relação profissional com ele pelo amparo que ele e sua rede de corruptores, aparentemente, proporcionavam a ela.

\subsection{Postura Cínica}

$\mathrm{Na}$ análise do vídeo 1, não identificamos nenhuma das táticas de racionalização propostas por Anand, Ashforth e Joshi (2004), no entanto, em nossa interpretação, o acusado utiliza uma postura cínica como uma tática de racionalização. Denominamos de postura cínica por entender que o cinismo envolve o conceito de ideologia cínica apresentada por Moura (2010), que afirma que essa opera não apenas na reafirmação do corte entre discurso e prática, mas, também, como uma forma de domínio prático, estruturando sua própria realidade. O cinismo, como definido por Niehues-Pröbsting (2007, p. 390), "é a rejeição consciente e demonstrativa de uma atitude moral exigida", e se instrumentaliza pela sátira e ironia, sendo que "a atitude moral é afastada e substituída, por exemplo, por uma atitude cômica” (NIEHUES-PRÖBSTING, 2007, p. 390).

No trecho do vídeo 01, a partir dos 00:31", o acusado afirma que: "Entre hotel, jantar e mulher, já cheguei a gastar R\$ 8 (mil), 10 mil reais". Quando perguntado pelo entrevistador se os gastos eram provenientes de "dinheiro da corrupção", ele afirma
“Isso!", demonstrando uma rejeição a uma atitude moral. Ainda no vídeo 01, o acusado, ao ser perguntado sobre como gastava os lucros que teve com o esquema de corrupção, através de duas falas, nos 05':30" do vídeo 01 , afirma que passou a ter compulsão sexual e que matinha um padrão de vida que não condizia com a sua realidade. Aos 07’:14" do vídeo 01, quando perguntado: "Se fosse só o dinheiro do teu salário, você não gastaria isso?", o acusado responde: "Não! Nem dava para fazer isso. Você não gasta com isso o dinheiro fruto do seu sacrifício, né? Gastava porque entrava. Eu quis viver." Prosseguindo, o entrevistador pergunta: "E viveu?". O acusado, então, responde "Vivi!".

Ainda no vídeo 01, a partir dos 09’:50", tem-se o seguinte diálogo:

Entrevistador: Você não se arrepende de ser um corrupto? Acusado: Essa pergunta, eu ainda não sei te responder. A ficha não caiu, né?

Entrevistador: Quem é o Alexandre corrupto?

Acusado: O Alexandre corrupto foi o que aceitou fazer parte dessa situação.

Entrevistador: Se você tivesse condições de devolver esse dinheiro, você devolveria?

Acusado: É, não dá para fazer isso, né? Como é que eu vou fazer?

Entrevistador: Nem teria como?

Acusado: Não teria como, só se eu bater na porta de um monte de moça por aí e tentar devolver e tal. Não tem como!

Analisando os trechos percebemos que o entrevistado usa em seu discurso uma fala que evidencia a consciência de conduta incorreta, no entanto, aparentemente, sem indícios de arrependimento pela consequência que suas ações causaram, demonstrando que a conduta corrupta foi incorporada em sua realidade, de uma forma que a ele o atendimento de suas necessidades pessoais se sobrepôs à lei e passou a ser mais importante que respeitar a legalidade, culminando, assim, na prática dos atos.

Nossa análise resultou na identificação de seis táticas de racionalização por parte dos envolvidos em esquemas de corrupção no Brasil. Dessas, quatro são coincidentes com aquelas encontradas por Anand, Ashforth e Joshi (2004): negação de responsabilidade, negação de dano, ponderações sociais, e metáfora do equilíbrio. Não encontramos 
a tática de negação da vítima, a qual ocorre quando o envolvido argumenta que a parte violada merece o que aconteceu, e nem a tática de apelo a lealdade elevada, que consiste na justificativa de que a viola- ção das normas ocorreu em uma tentativa de atender um valor de ordem superior.

No Quadro 03, a seguir, sintetizamos os resultados:

Quadro 03 Estratégias de racionalização utilizadas e os indicadores

\begin{tabular}{l|l|l}
\hline Estratégia & $\begin{array}{l}\text { Vídeos em que a estratégia } \\
\text { está presente }\end{array}$ & Exemplos \\
\hline $\begin{array}{l}\text { Negação de } \\
\text { responsabilidade }\end{array}$ & Vídeo 06. & $\begin{array}{l}\text { "A coisa era feita abertamente. Todo mundo sabia na empresa. As pessoas dentro } \\
\text { do departamento financeiro sabiam e algumas pessoas também fora sabiam } \\
\text { que a empresa sempre trabalhava com caixa dois". }\end{array}$ \\
\hline Negação de dano & Vídeo 05. & $\begin{array}{l}\text { "Não, eu sou o dono do dinheiro, não. Eu sou usufrutuário em vida, nas condições } \\
\text { determinadas". }\end{array}$ \\
\hline Ponderações sociais & Vídeos 02, 03, 04 e 10. & $\begin{array}{l}\text { "Por exemplo, acusação todo mundo tem, agora mesmo acusaram a Globo de } \\
\text { estar envolvida em um desvio milionário, laranjas e parásos fiscais, eu não sei se } \\
\text { a Globo é culpada eu até acho que é, mas é uma opinião minha, quem vai dizer } \\
\text { isso é o juiz, não sou eu, né" }\end{array}$ \\
\hline Negação do ato & Vídeos 07 e 10. & $\begin{array}{l}\text { "Não! Essa letra não é minha, esse recibo não fui eu quem fiz e essa letra não é } \\
\text { minha!" }\end{array}$ \\
\hline Metáfora do Equilíbrio & Vídeos 08 e 09. & $\begin{array}{l}\text { "O valor que o vereador ganha aqui, se ele não for corrupto, ele mal se sustenta } \\
\text { durante o mês". }\end{array}$ \\
\hline Postura cínica & Vídeo 01. & $\begin{array}{l}\text { Entrevistado afirma que passou a ter compulsão sexual e que matinha um } \\
\text { padrão de vida que não condizia com a sua realidade }\end{array}$ \\
\hline
\end{tabular}

Fonte: elaborado pelos autores com base na pesquisa

É importante destacar que a realidade retratada na análise que efetuamos é a dos acontecimentos ocorridos no Brasil entre 2013 e 2016. Os vídeos analisados foram selecionados a partir de veículos que possuem ampla cobertura no país e representam em sua grande maioria declarações que surgiram a partir de escândalos que envolvem a participação de agentes políticos, uma vez que estes casos receberam maior destaque da mídia no período.

Os achados sinalizam para as diferenças e semelhanças entre as estratégias de racionalização utilizadas pelos entrevistados no estudo original e pelos entrevistados nos vídeos analisados nesta pesquisa, ressaltando que nossa pesquisa analisou os discursos no âmbito brasileiro e pouco mais de uma década após a realização do estudo de Anand, Ashforth e Joshi (2004).

A partir de uma análise dos dois estudos percebemos que em nosso estudo, a tática de racionalização "negação de responsabilidade", a partir do exemplo escolhido (vídeo 06) traduz de forma literal a ação em uma organização claramente corrupta. A pessoa envolvida neste caso, diferentemente do exemplo utilizado no trabalho de Anand, Ashforth e Joshi (2004), não se disse forçada ou advertida por alguém a fazer o que estava fazendo, mas seguiu o que já era praticado como rotina pela empresa ou seja em seu discurso ela nega sua responsabilidade ao transferi-la à própria organização que integrava. $\mathrm{O}$ discurso da pessoa envolvida atribui a responsabilidade da corrupção à própria instituição, que de acordo com ela tinha benefícios com as práticas, o que corresponde ao conceito de corrupção organizacional apresentado por Pinto, Leana e Pil (2008).

Exemplificada através do vídeo 05 , a estratégia que aqui denominamos "negação do dano", apesar de analisada em um contexto distinto (contexto político) do que os autores do trabalho original fizeram (contexto corporativo), demonstra que sua essência é a mesma do trabalho original e consiste em minimizar e relativizar os danos e assim racionalizar a ação corrupta.

A racionalização denominada "ponderações sociais" e observada nos exemplos que utilizamos em 
nosso trabalho convergem ao primeiro ("condemning the condemners") dos dois tipos de ponderações sociais (condemn the condemner; selective social comparison), citadas pelos autores do artigo original. Nos vídeos analisados, observamos uma tendência nos discursos em racionalizar a corrupção praticada, por meio da desqualificação das instituições acusadoras, enquanto que a "sub-estratégia" denominada "comparação social seletiva" que é a minimização do efeito das próprias ações por meio da comparação com atos já praticados e considerados por eles, como piores que os seus próprios, não foi detectada em nenhum dos vídeos selecionados para análise.

A estratégia de "negação do dano" encontrada por Anand, Ashforth e Joshi (2004), foi utilizada para explicar a perpetuação da corrupção, ou seja, uma forma de racionalização dos entrevistados para continuarem a participar de esquemas de corrupção estando eles cientes de seus erros ou não, o que foi também evidenciado no caso brasileiro que foi exemplificada em nossa pesquisa pelos vídeos 07 e 10. Em nossa análise percebemos que o este tipo de estratégia possui um caráter de resposta imediata e o acusado pode utiliza-la, mas posteriormente em novo discurso modificar a estratégia de racionalização.

A estratégia "metáfora do equilíbrio" assim como a "negação do dano", também foi encontrada em nossos achados e a sua exemplificação representa não somente o nosso contexto, mas também aquele utilizado nas construção dos argumentos de Anand, Ashforth e Joshi (2004). Como fruto dos vídeos analisados surgiu ainda uma estratégia de racionalização que chamamos de "postura cínica", esta não havia sido apontada no trabalho de Anand, Ashforth e Joshi (2004), assim como a "negação do ato".

As categorias de estratégias levantadas, podem ser transpostas e observadas em outros ambientes organizacionais que não aqueles dos quais os acusados faziam parte, como Anand, Ashforth e Joshi (2004) fazem em seu trabalho ao citarem discursos utilizados no dia a dia do ambiente de grandes corporações ou mesmo de pequenas organizações. Além das noções de racionalização expressas nos discursos, tanto as táticas de institucionalização quanto a socialização da corrupção, descritas por Anand e Ashfort (2003) estão também presentes nos depoimentos, como no caso do vídeo 06 a admissão da corrupção como parte da rotina das organizações, assim como a estimulação à socialização das práticas corruptas.

Entendemos que os achados de nossa pesquisa vão ao encontro das alegações feitas por Brei (1996) em seu trabalho quando afirma que algumas dimensões relacionadas a corrupção são socialmente aceitas pelos indivíduos, no caso de nossa pesquisa, os acusados em esquemas de corrupção podem ter sua atitude e a tentativa de racionalizar suas práticas justificadas pelos exemplos citados pela autora como sua condição social e as recompensas financeiras obtidas quando da prática dos atos.

\section{CONSIDERAÇÕES FINAIS}

Nessa pesquisa, lançamos nosso olhar para o tema corrupção e a perpetuação de sua prática nas organizações, colocando como central o modo como as pessoas tentam convencer (a si ou aos outros) que suas táticas de racionalização são suficientes para justificar sua participação em práticas ilegais e antiéticas, neste caso, esquemas de corrupção. As táticas de racionalização podem ser invocadas antes do ato ou depois do ato. O que é preciso levar em consideração é o fato de que essas podem tonar-se parte da cultura organizacional, potencializando sua naturalização.

Nas entrevistas dos envolvidos em esquemas de corrupção analisadas, nós identificamos as seguintes táticas de racionalização utilizadas pelos acusados: a negação de responsabilidade, a negação de dano, as ponderações sociais, a negação do ato, a metáfora de equilíbrio e a postura cínica. Essas demonstram que, quando há um questionamento por parte dos envolvidos nos esquemas, cada um expõe sua versão do fato e, embora muitos até contestem as acusações, o que não deixa de ser uma forma de discurso, outros, de acordo com suas realidades e interpretações de mundo, acabam criando pontos em comum em seus discursos, que parecem surgir como resultado das interações e articulações sociais que os envolvem e que podem contribuir para a elaboração de um cenário favorável à continuidade de práticas de corrupção.

Nossa pesquisa traz implicações teóricas ao acrescentar novos referenciais, o cinismo e a negação do ato, para compreender a racionalização das pessoas envolvidas em práticas ilegais e antiéticas, como 
os esquemas de corrupção, e as táticas utilizadas para sua perpetuação, o que entendemos como uma contribuição relevante para o campo dos estudos organizacionais. Esse achado pode estimular outras pesquisas no campo, como, por exemplo, investigar como se manifestam emoções como culpa e arrependimento nos envolvidos, quando esses invocam táticas de racionalizações. Outra possibilidade de pesquisa é a identificação de táticas de racionalização invocadas prospectivamente, ou seja, antes de ocorrer a prática ilegal ou antiética.

\section{REFERÊNCIAS}

AMUNDSEN, I. Political Corruption: an introduction to the issues. Bergen: Chr. Michelsen Institute, 1999.

ASHFORT, B. E; ANAND, V. The Normalization of Corruption in Organizations. Research in Organizational Behavior. v. 25, p. 1-52.2003.

ANAND, V.; ASHFORTH, B. E. e JOSHI, M. Business as usual: The acceptance and perpetuation of corruption in organizations.Academy of Management Executive. vol. 18, n. 2. 2004.

ASHFORTH, B. E.; GIOIA, D. A.; ROBINSON, S. L.; TREVIÑO, L. K. Re-Viewing Organizational Corruption. Academy of Management Review. v. 33, n. 3, p. 670-684, 2008.

BREI, Z. A. A corrupção: causas, conseqüências e soluções para o problema. Revista de Administração Pública. Rio de Janeiro, v. 30, n. 3.1996.

BREI, Z. A. Corrupção: dificuldades para definição e para um consenso. Revista de Administração Pública. Rio de Janeiro, v.30, Jan/Fev.1996.

CHADDA, M. 'India: Between Majesty and Modernity', em R. A. Johnson (ed.), The Struggle Against Corruption. Nova York: Palgrave Macmillan, pp. 109-43.2004.
FLICK, U. Desenho da pesquisa qualitativa. Coleção Pesquisa Qualitativa (Coordenação de Uwe Flick). Porto Alegre: Bookman, Artmed, 2009.

FILGUEIRAS, F. A tolerância à corrupção no Brasil: uma antinomia entre normas morais e prática social. Opinião Pública. vol. 15, nº 2, p.386-421. Campinas. Novembro.2009.

FISCHER, R.; FERREIRA, M. C.; MILFONT, T. e PILATI, R. Culture of Corruption? The Effects of Priming Corruption Images in a High Corruption Context. Journal of Cross-Cultural Psychology. vol 45, ed.10, p. 1594-1605. 2014.

G1. Vereador que reclamou de salário é preso em operação contra fraudes, maio/2015. Disponível em: < http://g1.globo.com/pa/para/noticia/2015/05/ vereador-que-reclamou-de-salario-e-preso-em-operacao-contra-fraudes.html> . Acesso em: 20 mai.2016.

HUntington, S. P. A Ordem Política nas Sociedades em Mudança. São Paulo: Ed. USP. 1975.

IT. International Transparency (Transparência Internacional). 2016. Disponível em <http://www. transparency.org/what-is-corruption $>$. Acesso em 09/11/2016.

JIANG, G.; LO, T. W. e LI, C. Youths' Views on Corruption Control in China: Politics and Social Censure. International Journal of Offender Therapy and Comparative Criminology. v. 57, $\mathrm{n}^{\circ} .12$, p. 1498-1521.2012.

LAMBSDORFF, J. G. Causes and consequences of corruption: What do we know from a cross-section of countries? In: ROSE-ACKERMAN, S. International Handbook on the economics of corruption, Northampton: Edward Elgar Publish, 2006, p. 3-51.

MAEDA, K. e ZIEGFELD, A. Socioeconomic status and corruption perceptions around the world. Research and Politics.Abr-Jun. p.1- 9,2015. 
MOURA, A. C. O Cinismo E Os Desmandos Da Razão: Algumas Questões Sobre A Racionalidade Formal. Kínesis, vol. II, n 03, Abril, p.331-344.2010.

NIEHUES-PRÖBSTING, H. “A Recepção Moderna do Cinismo: Diógenes no iluminismo". In: BRANHAM; GOLUET-CAZÉ (orgs.) Os Cínicos: o movimento na antiguidade e o seu legado. São Paulo: Loyola, 2007.

NUMERATO, D. Corruption and public secrecy: An ethnography of football match-fixing. Current Sociology. v. 64, n. 15, p. 1-19, 2016.

O'CONNOR, S.; FISCHER, R. Predicting Societal Corruption Across Time: Values, Wealth, or Institutions? Journal of Cross-Cultural Psychology, Newbury Park, v. 43, n. 4, p. 644-659, May 2012.

OLIVEIRA, R. R. Contabilidade, controle interno e controle externo: trinômio necessário para combater a corrupção. Pensar Contábil. v. 8, n.31, p. 2-9, 2006.

PINTO, J; LEANA, C. R; PIL, F. K. Corrupt Organizations or Organizations of Corrupt Individuals? Two Types of Organization-Level Corruption. Academy of Management Review. v. 33, n. 3, p. 685-709, 2008.

ROSE-ACKERMAN, S. International Handbook on the Economics of Corruption. Massachusetts: Edward Elgar, 2006.

SCHWARTZMAN, S. Coesão Social, Democracia e Corrupção. iFHC/CIEPLAN. São Paulo, Brasil, e Santiago de Chile.2008.

SILVA, M. Corrupção: tentativa de uma definição funcional. Revista de Administração Pública, Rio de Janeiro, v. 28, n. 1, p. 18-23, jan./mar. 1994.
SILVA, A. M. C; BRAGA, E. C; LAURENCEL, L. C. A Corrupção em uma Abordagem EconômicoContábil e o Auxílio da Auditoria como Ferramenta de Combate. Revista Contabilidade Vista \& Revista. v. 20, n. 1, p. 95-117, jan./mar. 2009.

SILVA, P. J; PEREIRA, M. C; BRITO, M. J; CAPELLE, M. C. A. A Ação Corrupta Em Uma Organização Multinacional: Uma Análise Sob A Ótica Da Abordagem Construcionista. REAd .v. 11 No. 6, nov-dez. 2005.

TANZI, V. Corruption Around the World: Causes, Consequences, Scope and Cures. IMF Staff Paper. Ed. 45 (4), p.559-594.1998.

TILLMAN, R. Making the rules and breaking the rules: The political origins of corporate corruption in the new economy.Business Media. v. 51, n. 01, fevereiro.2009.

TRANSPARENCY INTERNATIONAL. 2015. What is corruption? Disponível em: $<$ https://www.transparency.org/what-is-corruption $>$. Acesso em: 01 abr. 2016.

TORSELLO, D. e VERNARD, B. The Anthropology of Corruption. Journal of Management Inquiry. p. 1-21. 2015.

VERGARA, S. C.; CALDAS, M. P. Paradigma interpretacionista: a busca da superação do objetivismo funcionalista nos anos 1980 e 1990. In: CALDAS, M. P.; BERTERO, C. O. (coord). Teoria das Organizações. São Paulo: Atlas. 2007.

WORLD BANK GROUP. Worldwide Governance Indicators. Disponível em: < http://info.worldbank. org/governance/wgi/index.aspx\#reports $>$. Acesso em: 30 ago. 2017. 